\title{
El surgimiento de una economía capitalista de subsistencia en el Perú
}

\author{
Jan Lust \\ Universidad Ricardo Palma \\ jan.lust @urp.edu.pe
}

\begin{abstract}
RESUMEN
La economía peruana depende para su crecimiento de la exportación de sus recursos minerales. Esta dependencia se deriva del rol del país en la división internacional del trabajo y se expresa en su estructura de exportación, en su estructura económica y en su estructura empresarial. La dependencia del Perú de sus recursos minerales, una estructura económica que está compuesta, principalmente, por sectores no transables y una estructura empresarial dominada por microempresas, hace que el progreso económico duradero sea muy difícil. Argumentamos que la economía peruana está dividida en una economía avanzada y una economía capitalista de subsistencia (ECS). Esta característica estructural de la economía peruana impide la implementación exitosa de un proceso que haría al país menos dependiente de sus recursos naturales y lo podría colocar en un camino hacia un desarrollo basado en una mayor producción de valor agregado.
\end{abstract}

Palabras Clave: Economía capitalista de subsistencia, economía avanzada, microempresas, población económicamente activa, mercado interno

\section{Rise of a subsistence capitalist economy in Peru}

\begin{abstract}
The Peruvian economy depends on the export of its mineral resources for its growth. This dependence comes from the role of the country in the international division of labor and is expressed in its export, economic and business structure. Peru dependence on its mineral resources, an economic structure made up mainly of non-tradable sectors and a business structure dominated by micro-enterprises, which makes lasting economic progress very difficult. We argue that the Peruvian economy is divided into an advanced economy and a subsistence capitalist economy (ECS). This structural characteristic of the Peruvian economy prevents the successful implementation of a process that would make the country less dependent on its natural resources and could place it on a path towards development based on greater added value production.
\end{abstract}

KeYwords: subsistence capitalist economy, advanced economy, micro-enterprises, economically active population, internal market 


\section{Introducción ${ }^{1}$}

La economía peruana depende para su crecimiento de la exportación de sus recursos minerales. Esta dependencia se deriva del rol del país en la división internacional del trabajo. La dependencia del Perú de sus recursos minerales está claramente demostrada en su estructura de exportación. En el periodo 1980-2015, la participación de los productos mineros en el valor total de las exportaciones fue entre 50\% y $60 \%$.

La función del Perú en el mundo capitalista globalizado no es la consecuencia de la posesión de abundantes materias primas necesarias para el desarrollo capitalista en el Norte global, sino el resultado histórico de tener su propio desarrollo (capitalista) cortado por la explotación y opresión colonial. El país entró en la arena capitalista mundial sin haber desarrollado, en forma capitalista, sus propios procesos productivos y fue sometido a las necesidades de las corporaciones en lo que podría llamarse el Norte global² (Frank, 1971; Mandel, 1975, p. 76; Yepes del Castillo, 1972, p. 32-33; Emmanuel, 1976, p. 24).

La dependencia del país de la exportación de sus productos mineros no solo se expresa en su estructura de exportación, sino también en su estructura económica y empresarial. La mayoría de los bienes transables pertenecen a los sectores extractivos de la economía y el sector manufacturero tiene una reducida importancia para el crecimiento económico. Además, el predominio de los sectores no transables (electricidad y agua, construcción, comercio y la mayoría de los servicios) en el Producto Bruto Interno (PBI) demuestra que la producción no se centra en bienes y servicios exportables de alto valor agregado.

Los flujos de Inversión Extranjera Directa (IED) revelan que el empresariado internacional se ha interesado principalmente por los sectores extractivos de la economía, la comunicación y las finanzas. ${ }^{3}$ Las empresas estatales con proyecciones de inversión más altas que se privatizaron en la década de 1990 fueron aquellas que operaron en los sectores de minería, de hidrocarburos y de telecomunicaciones (Ruiz Caro, 2002, pp. 28-29). En relación a la IED y los movimientos internacionales de capital en general, es importante subrayar que estos movimientos no solo resultan en

1 El presente trabajo es uno de los primeros resultados de la investigación sobre las condiciones laborales de los trabajadores y empleados en pequeńas y microempresas en el Perú en el periodo 1980-2015. En 2017 el proyecto de investigación fue aprobado por el Consejo Universitario de la Universidad Ricardo Palma.

2 El Norte global consiste en aquellos países que solían llamarse países capitalistas avanzados. Los países capitalistas avanzados forman parte de la Organización para la Cooperación y el Desarrollo Económico (OCDE). Sin embargo, no todos los Estados miembros de la OCDE son países capitalistas avanzados. Aunque China no se considera un país capitalista avanzado y no pertenece a la OCDE, en base a su poder económico global lo consideramos como parte del Norte global.

3 Se debe mencionar que la industria ocupó el quinto lugar en la lista del saldo de la IED en los ańos comprendidos entre 1980 y 2016. La minería, la comunicación, las finanzas y la energía ocuparon los puestos uno a cuatro. Fuente: http://www.proinversion.gob.pe/modulos/LAN/landing.aspx?are=0\&pfl=1\&lan=10\&tit=proinversi $\% \mathrm{C} 3$ $\%$ B3n-institucional (consultado 26/10/2017). 
la división internacional del trabajo en particular, sino que esta división internacional del trabajo en sí ayuda a configurar, por su parte, las particularidades de estos flujos de capital.

La relación entre el papel del país en la división internacional del trabajo y los flujos internacionales de capital se reflejan en la parte superior de la estructura empresarial del país. Según los datos de la revista América Economía, las principales empresas que operan en el país son las corporaciones en los sectores extractivos de la economía. Además, mientras que en la década de 1990 las cinco principales corporaciones que operaban en Perú eran nativas, desde el año 2000 el capital extranjero domina el ranking de las cinco principales empresas en el Perú.

La mayoría absoluta de las empresas peruanas se encuentran dentro de la categoría de microempresas. Su contribución a la producción nacional total es extremamente pequeña. ${ }^{4}$ En 2007, por ejemplo, los datos revelan que las microempresas produjeron $5,9 \%$ de la producción total en el país. Las empresas medianas y grandes produjeron el 85,3\% de la producción total (INEI, 2008, p. 37). En 2013, de acuerdo con la información del INEI (2013a), se esperaba que la participación de las microempresas en las ventas anuales totales sería 5,6\%. La contribución de las microempresas al valor de las exportaciones totales es insignificante. En 2014, el 60,8\% de todas las empresas exportadoras eran microempresas. Su contribución al valor total de las exportaciones fue $0,6 \% .^{5}$

La dependencia del país de sus recursos minerales, una estructura económica que está compuesta primordialmente por los sectores no transables y una estructura empresarial dominada por microempresas, hace que sea muy difícil el progreso económico duradero. Varios autores han explicado que los modelos de desarrollo extractivo no garantizan un progreso prolongado y estructural (Prebisch, 1949, Lewis, 1955, Rostow, 1961, Furtado, 1980, Gudynas, 2011). Economistas peruanos como Jiménez (2010), Dancourt (2016) y Gonzales de Olarte (2007) consideran la industrialización, la diversificación del aparato productivo del país, el retorno del papel del Estado en la economía (aumentando las inversiones públicas, redistribuyendo el ingreso, etc.) y el desarrollo del mercado interno, entre otros, cruciales para un desarrollo económico sólido.

En el corto plazo es muy difícil transformar estructuralmente la economía peruana. Creemos que el surgimiento de una economía capitalista de subsistencia (ECS) en el

4 La definición de microempresas, pequeńas empresas, medianas empresas y grandes empresas se basa, desde 2013, principalmente, en las ventas anuales. Una microempresa se valora a una tasa máxima de 150 Unidades Impositivas Tributarias. La venta anual de una pequeña empresa se encuentra entre 150 y 1.700 Unidades Impositivas Tributarias. Las ventas de empresas medianas y grandes se consideran superiores a 1700 Unidades Impositivas Tributarias. El valor de 1 (una) Unidad Impositiva Tributaria varía año por año. Por ejemplo, mientras en 20121 UIT fue 3.650 soles, en 2016 fue 3.950 soles.

5 Fuente: ADEX, PymeNews, Febrero 2015, en http://prueba.adexdatatrade.com/Members/Boletines.aspx?g=12 (consultado 09/08/2017). 
Perú impide la implementación exitosa de un proceso que haría al país menos dependiente de sus recursos naturales y lo colocaría en un camino hacia un desarrollo basado en una mayor producción de valor agregado.

Este artículo está organizado en cuatro partes. La parte 1 define la ECS y describe sus características. La parte 2 explica las funciones de la ECS para la economía avanzada y en la parte 3 discutimos el mercado interno de la ECS. Finalmente, en la parte 4 se presentan nuestras conclusiones.

\section{Definición y características de la ECS}

La economía peruana puede definirse como una economía que se divide en una economía al servicio de las grandes corporaciones privadas —especialmente las empresas transnacionales en el sector extractivo- y una economía de microempresas caracterizada por bajos niveles de productividad expresada en tasas de remuneración iguales o cercanas (inferiores o superiores) al nivel del salario mínimo. ${ }^{6}$ La primera economía la nombramos como una economía avanzada y la segunda una ECS. ${ }^{7}$

Tabla 1: La distribución de la PEA por grupos de tamańo empresarial (ocupación principal de los trabajadores / empleados) en Lima Metropolitana: 1986-1995 (como porcentaje de la

PEA total en Lima Metropolitana) $)^{8}$

\begin{tabular}{|l|l|l|l|l|l|l|l|l|l|l|}
\hline $\begin{array}{l}\text { Tamańo de } \\
\text { empresas según } \\
\text { la cantidad de } \\
\text { personas empleadas }\end{array}$ & 1986 & 1987 & $1988^{*}$ & 1989 & 1990 & 1991 & 1992 & 1993 & 1994 & 1995 \\
\hline 1 persona & $23,3 \%$ & $21,6 \%$ & - & $22,5 \%$ & $24,0 \%$ & $27,9 \%$ & $27,5 \%$ & $25,8 \%$ & $25,2 \%$ & $24,3 \%$ \\
\hline $2-4$ personas & $25,0 \%$ & $24,2 \%$ & - & $23,4 \%$ & $25,4 \%$ & $23,1 \%$ & $25,0 \%$ & $26,3 \%$ & $26,7 \%$ & $27,3 \%$ \\
\hline $5-9$ personas & $9,0 \%$ & $8,5 \%$ & - & $7,8 \%$ & $8,1 \%$ & $7,1 \%$ & $7,5 \%$ & $8,4 \%$ & $7,9 \%$ & $9,8 \%$ \\
\hline $10-19$ personas & $5,9 \%$ & $5,6 \%$ & - & $4,8 \%$ & $5,7 \%$ & $5,3 \%$ & $6,0 \%$ & $5,8 \%$ & $6,2 \%$ & $5,6 \%$ \\
\hline $20-49$ personas & $6,6 \%$ & $6,1 \%$ & - & $7,0 \%$ & $6,9 \%$ & $5,9 \%$ & $6,7 \%$ & $6,4 \%$ & $6,7 \%$ & $6,1 \%$ \\
\hline $50-99$ personas & $4,6 \%$ & $3,7 \%$ & - & $4,3 \%$ & $4,2 \%$ & $4,4 \%$ & $4,1 \%$ & $4,1 \%$ & $4,6 \%$ & $3,9 \%$ \\
\hline $100-499$ personas & $8,0 \%$ & $8,7 \%$ & - & $7,4 \%$ & $6,4 \%$ & $7,7 \%$ & $7,5 \%$ & $7,3 \%$ & $7,2 \%$ & $8,6 \%$ \\
\hline 500 y más personas & $17,6 \%$ & $21,6 \%$ & - & $22,8 \%$ & $19,3 \%$ & $18,6 \%$ & $15,8 \%$ & $15,9 \%$ & $15,5 \%$ & $14,3 \%$ \\
\hline Total & $100 \%$ & $100 \%$ & - & $100 \%$ & $100 \%$ & $99,8 \%$ & $100,1 \%$ & $100 \%$ & $100 \%$ & $100,1 \%$ \\
\hline
\end{tabular}

Fuente: Ministerio de Trabajo, Encuesta de Hogares, Lima Metropolitana, 1986, 1987, 1989-1995.

* Datos no disponibles para 1988.

6 Véase para la relación entre el ingreso laboral y la productividad, Saavedra (1999, pp. 36-37). Sobre las diferencias de productividad dentro de la economía peruana y entre las empresas de diferentes tamaños de acuerdo al número de personas empleados, ver Gonzales de Olarte (2016, pp. 274-275), Cavero (2017, pp. 38-39) y Díaz (2014, pp. 197-198).

7 Se debe subrayar que el empresariado internacional forma parte de la economía avanzada. Ver Jiménez (2012, pp. 63-64) para un análisis comparativo de lo que hemos denominado una ECS. Jiménez llama a esta economía, siguiendo el trabajo de Matos Mar (2012), "Otro Perú”.

8 Las diferencias de redondeo hacen que los porcentajes estén ligeramente por encima o por debajo del 100\%. 
La economía avanzada y la ECS son economías monetarias, la producción está impulsada por las ganancias y el mercado es el principal mecanismo de distribución. Esta división no se reduce a un sector en particular, sino que todos los sectores económicos se dividen en una economía avanzada y un CSE (INEI, 2013b; 2014; 2016a; 2017). En las tablas 1 y 2 se presentan datos sobre la distribución de la Población Económicamente Activa (PEA) por grupos de tamaño empresarial en los períodos 1986-1995 (Lima Metropolitana) y 1997-2014 (Perú).

Tabla 2: La distribución de la PEA por grupos de tamaño empresarial (ocupación principal de los trabajadores / empleados) en el Perú: 1998-2014 (como porcentaje de la PEA ocupada en el Perú) ${ }^{9}$

\begin{tabular}{|c|c|c|c|c|c|c|c|c|c|}
\hline $\begin{array}{l}\text { Tamaño de } \\
\text { empresas según } \\
\text { la cantidad de } \\
\text { personas empleadas }\end{array}$ & 1998 & 1999 & 2000 & 2001 & 2002 & 2003 & 2004 & 2005 & 2006 \\
\hline 1 persona & $23,5 \%$ & $22,9 \%$ & $23,8 \%$ & $21,2 \%$ & $21,5 \%$ & $21,4 \%$ & $20,3 \%$ & $19,5 \%$ & $19,3 \%$ \\
\hline 2-4 personas & $46,7 \%$ & $45,5 \%$ & $45,0 \%$ & $48,0 \%$ & $46,8 \%$ & $46,9 \%$ & $46,6 \%$ & $47,2 \%$ & $46,5 \%$ \\
\hline 5-9 personas & $11,5 \%$ & $12,7 \%$ & $10,9 \%$ & $11,7 \%$ & $12,2 \%$ & $13,9 \%$ & $14,9 \%$ & $14,8 \%$ & $15,1 \%$ \\
\hline 10-19 personas & $3,2 \%$ & $3,3 \%$ & $3,3 \%$ & $3,6 \%$ & $3,1 \%$ & $3,1 \%$ & $3,5 \%$ & $3,9 \%$ & $3,5 \%$ \\
\hline 20-49 personas & $2,2 \%$ & $2,6 \%$ & $2,7 \%$ & $2,6 \%$ & $2,5 \%$ & $2,5 \%$ & $2,4 \%$ & $2,3 \%$ & $2,6 \%$ \\
\hline 50-99 personas & $1,2 \%$ & $1,3 \%$ & $1,4 \%$ & $1,3 \%$ & $1,4 \%$ & $1,2 \%$ & $1,2 \%$ & $1,2 \%$ & $1,3 \%$ \\
\hline $100-499$ personas & $2,1 \%$ & $1,9 \%$ & $1,7 \%$ & $2,1 \%$ & $2,0 \%$ & $1,8 \%$ & $2,0 \%$ & $1,9 \%$ & $2,0 \%$ \\
\hline 500 y más personas & $9,6 \%$ & $9,8 \%$ & $11,2 \%$ & $9,4 \%$ & $10,4 \%$ & $9,1 \%$ & $9,2 \%$ & $9,1 \%$ & $9,6 \%$ \\
\hline Total & $100 \%$ & $100 \%$ & $100 \%$ & $99,9 \%$ & $99,9 \%$ & $99,9 \%$ & $100,1 \%$ & $99,9 \%$ & $99,9 \%$ \\
\hline $\begin{array}{l}\text { Tamaño de } \\
\text { empresas según } \\
\text { la cantidad de } \\
\text { personas empleadas }\end{array}$ & 2007 & 2008 & 2009 & 2010 & & & 2012 & 2013 & 2014 \\
\hline 1 persona & $20,0 \%$ & $19,8 \%$ & $19,4 \%$ & 19,2 & & & $19,2 \%$ & $19,7 \%$ & $19,7 \%$ \\
\hline 2-4 personas & $45,5 \%$ & $44,7 \%$ & $45,1 \%$ & 45,1 & & & $44,9 \%$ & $44,5 \%$ & $45,0 \%$ \\
\hline 5-9 personas & $14,1 \%$ & $14,6 \%$ & $14,4 \%$ & 14,6 & & & $13,5 \%$ & $13,0 \%$ & $12,2 \%$ \\
\hline 10-19 personas & $3,6 \%$ & $3,7 \%$ & $3,7 \%$ & $3,6 \%$ & & & $3,7 \%$ & $3,4 \%$ & $3,5 \%$ \\
\hline 20-49 personas & $2,6 \%$ & $2,7 \%$ & $2,8 \%$ & $2,8 \%$ & & & $2,8 \%$ & $2,8 \%$ & $2,7 \%$ \\
\hline 50-99 personas & $1,3 \%$ & $1,2 \%$ & $1,3 \%$ & $1,3 \%$ & & & $1,5 \%$ & $1,6 \%$ & $1,6 \%$ \\
\hline 100-499 personas & $2,2 \%$ & $2,3 \%$ & $2,4 \%$ & $2,4 \%$ & & & $2,5 \%$ & $2,7 \%$ & $2,6 \%$ \\
\hline 500 y más personas & $10,6 \%$ & $10,9 \%$ & $10,9 \%$ & 10,9 & & & $12,0 \%$ & $12,2 \%$ & $12,6 \%$ \\
\hline Total & $99,9 \%$ & $99,9 \%$ & $100 \%$ & 99,9 & & $3 \%$ & $100,1 \%$ & $99,9 \%$ & $999 \%$ \\
\hline
\end{tabular}

Fuente: Instituto Nacional de Estadística e Informática, Encuesta Nacional de Hogares, 1998-2014.

El surgimiento de la ECS es producto de la división internacional del trabajo que provocó que una parte de la economía peruana se ligara fuertemente al desarrollo capitalista mundial en general y al capital internacional en particular. Es decir, la división

9 Las diferencias de redondeo hacen que los porcentajes estén ligeramente por encima o por debajo del $100 \%$. 
internacional de trabajo proporcionó la base estructural para el ascenso de la ECS. Las crisis económicas y la lucha por la supervivencia en los años ochenta, y la restructuración de las corporaciones en los ochentas y noventas en el contexto de una ausencia total de un sistema de seguridad social contribuyeron a su aparición en el país.

Las personas que están empleadas en la ECS reciben una remuneración que parece no ser suficiente para la reproducción de su fuerza laboral. Esto es lo que se llama sobreexplotación (Marini, 1985). Aunque no se dispone de información precisa sobre los costos de reproducción de la fuerza de trabajo, en base a los datos sobre la línea de pobreza se puede concluir que un gran número de personas en la ECS está sobreexplotado.

En 2016, la línea de pobreza (la canasta de alimentos básicos) para una familia de cuatro personas se situó en 1312 soles (328 soles por individuo). El salario mínimo nominal fue 900 soles. Si bien el salario mínimo nominal es suficiente para financiar la canasta mensual de alimentos básicos de una persona, este salario no resulta ser suficiente para reproducir su fuerza laboral porque no llega a cubrir los gastos de alquiler de vivienda, electricidad, gas, agua, transporte y educación, entre otros. El hecho de que alrededor del $70 \%$ de la población trabajadora peruana es informal y de la cual, suponemos, la mayoría gana un salario inferior al salario mínimo nominal, también podría indicar que un gran número de personas está sobreexplotado.

Gráfico 1: Salario mínimo nominal y remuneración nominal promedio de las personas que trabajan en empresas que emplean de 1 a 10 personas: 2001-2012 (en soles)

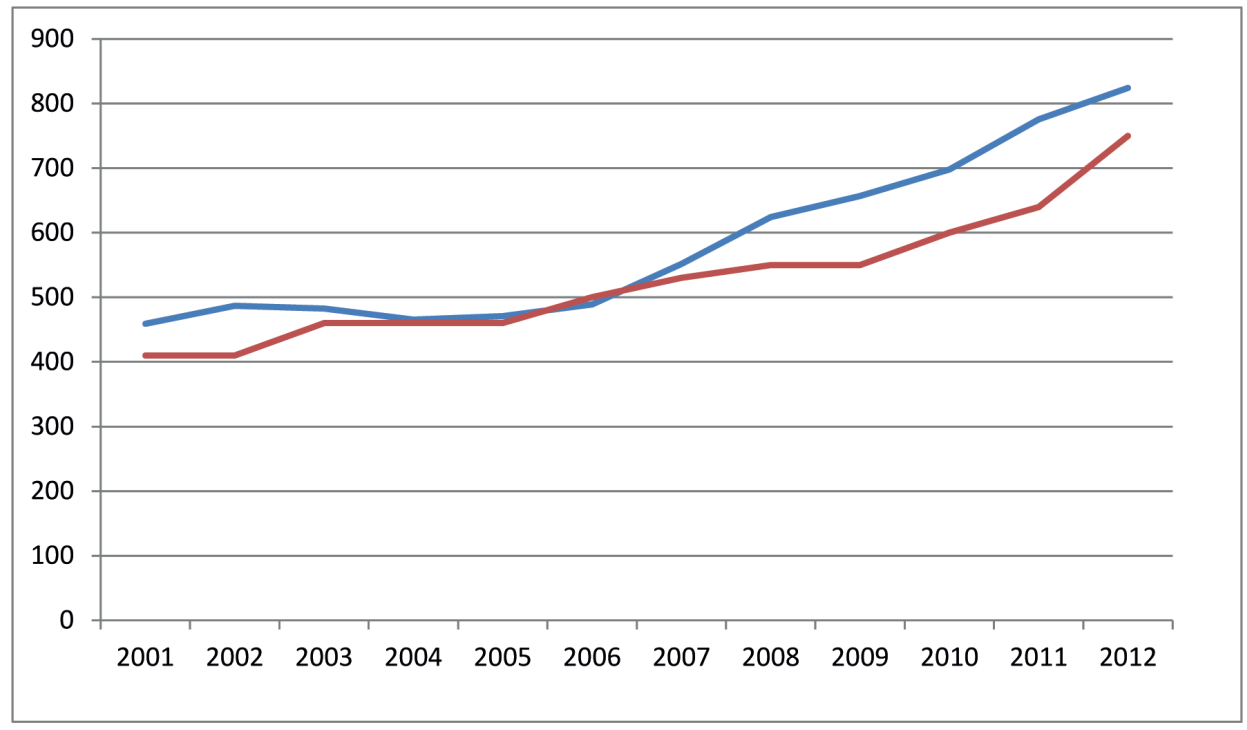

Fuentes: http://series.inei.gob.pe:8080/sirtod-series/ y www.mintra.gob.pe (consultado 06/08/2017).

Línea roja: salario mínimo nominal.

Línea azul: remuneración promedia nominal. 
Como hemos visto en las tablas 1 y 2, la gran mayoría de la PEA trabaja en empresas de 1 a 9 trabajadores y/o empleados. Las personas que trabajan en estos emprendimientos ganan, según los datos del Instituto Nacional de Estadística e Informática (INEI), un sueldo o salario alrededor del nivel del salario mínimo nominal. En el gráfico 1, el nivel salarial mínimo nominal se compara con la remuneración nominal promedio de las personas que trabajan en empresas que emplean de 1 a 10 personas. ${ }^{10}$

La sobreexplotación en los países periféricos del desarrollo capitalista mundial está condicionada por el papel de estos países en la división internacional del trabajo. Como son esencialmente proveedores de las materias primas para el desarrollo capitalista en el Norte global, grandes industrias que producen altos niveles de valor agregado no parecen ser necesarias. Según Gonzales de Olarte (2016, p. 208), la estructura de la economía peruana se caracteriza por tener una "relativa baja capacidad de generar valor agregado". ${ }^{11}$

La sobreexplotación solo se convierte en realidad en circunstancias específicas. En el caso del Perú, la sobreexplotación es una realidad para la mayoría de la población trabajadora debido a (i) la debilidad del movimiento laboral; (ii) la enorme cantidad de trabajadores y empleados poco calificados que compiten entre sí por pequeños trabajos temporales; y, (iii) la ferocidad de la competencia de precios entre la gran cantidad de microempresas. ${ }^{12}$ Además, aunque las personas sobreexplotados producen para "su propio mercado" y para el mercado de la economía avanzada, esto no impide que "sus empresas" paguen salarios por debajo de los costos de la reproducción de su fuerza de trabajo. El efecto negativo individual de la sobreexplotación, salarios y sueldos que son demasiados bajos para reproducir su propia fuerza laboral, se "resuelve" por el sistema de crédito y por el hecho de compartir el hogar con otras personas, entre otras medidas.

La ECS es similar a lo que se llama una economía de subsistencia, en el sentido de que el excedente económico es mínimo y las actividades económicas empleadas están destinadas a la reproducción de la supervivencia; es decir, las empresas de la ECS no tienden a reproducirse a escala ampliada. Las empresas en la ECS son negocios que, en general, no invierten en capital humano o en el desarrollo tecnológico. ${ }^{13}$ No solo el nivel de las ganancias parece ser demasiado bajo para invertir en máquinas, por ejemplo, sino que los bajos costos salariales no "estimulan" a estas empresas a reemplazar trabajadores por maquinas o adicionar maquinas más modernas a la fuerza laboral existente. Como es de esperar, la IED no está dirigida a las empresas en la ECS.

10 Solo datos disponibles hasta 2012.

11 Ver sobre este tema también Jiménez (2012, p. 59).

12 En 2016, el INEI (2017, p. 7) registró 2.116.973 empresas privadas. El 95\% de estos negocios fueron microempresas.

13 Bebbington (2013, p. 7) argumenta que en los países dependientes de los minerales, la educación “invierte poco en la formación de capital humano de base amplia porque el modelo extractivo de desarrollo no necesita esta forma de trabajo". 
La ECS no es lo mismo que el sector informal de la economía. La informalidad no solo es un problema en la ECS, sino también en la economía avanzada. Sin embargo, un país cuya economía está dividida en una economía avanzada y una ECS, a menudo también se caracteriza como una economía con un gran sector informal. La mayor parte de la economía informal forma parte de la ECS.

\section{La funcionalidad de la ECS para la economía avanzada}

La división de la economía peruana en una economía avanzada y una ECS parece implicar que la economía peruana es una economía dual. ${ }^{14}$ Las diferencias en las tecnologías empleadas, en el desarrollo del capital humano y en la estructura del mercado apuntan a dos sub-economías que funcionan por separado. Sin embargo, este supuesto dualismo no significa que estas economías estén funcionalmente separadas entre sí para la producción de valor. En otras palabras, aunque la economía peruana se manifiesta como una economía dual, es orgánicamente unificada ya que ambas sub-economías están íntimamente ligadas y se necesitan mutuamente para su existencia y reproducción.

La ECS es funcional para el desarrollo de la economía avanzada. Ciertas tareas productivas se subcontratan a las empresas que operan en la ECS para reducir costos en la economía avanzada. La ECS es un proveedor clave de mano de obra y materiales (a bajo costos) para la economía avanzada.

La relación entre la economía avanzada y la ECS parece similar a la relación entre los países capitalistas avanzados y las naciones en la periferia del desarrollo capitalista mundial, y la relación entre las metrópolis nacionales y los satélites dentro de un país subdesarrollado por otra. En su trabajo "El desarrollo del subdesarrollo", Frank (1966, p. 20) describe estas relaciones de la siguiente manera: "Del mismo modo que la capital colonial y nacional, y su sector exportador, se convierte en satélite de las metrópolis ibéricas (y posteriormente de otras) del sistema económico mundial, dicho satélite se convierte, a su vez, en metrópolis colonial, primero, y nacional, después, en relación al sector productivo y a la población del interior. Además, las capitales provinciales, que son a su vez satélites de la metrópolis nacional y, a través de esta, de las metrópolis mundiales, son a su vez centros provinciales alrededor de los cuales giran los satélites locales. Por lo tanto, toda una cadena de constelaciones de metrópolis y satélites relaciona todas las partes del conjunto del sistema, desde su centro metropolitana en Europa o en los Estados Unidos hasta el punto más alejado del campo o de la selva latinoamericana."15

14 Ver sobre el dualismo económico, Cypher y Dietz (2009, pp. 100-102).

15 La traducción está tomada de la versión castellano que apareció en 1966 en Monthly Review Selecciones en castellano. 
La ECS es el principal proveedor de los bienes y servicios para la reproducción de la fuerza laboral en la economía avanzada. Como produce estos productos a bajo costos, esta producción ayuda a reducir los gastos de mano de obra en la economía avanzada.

Las empresas en la ECS funcionan como una red de seguridad para todas aquellas personas que no han podido encontrar empleo en la economía avanzada. ${ }^{16}$ Entonces, se podría argumentar que en el Perú el ejército de reserva de mano de obra no solo abarca al desempleado y el subempleado, sino a todas las personas que están empleadas en la ECS. Palma (1988, p. 37) explica que los países que se encuentran en la periferia del sistema capitalista mundial tienen un excedente permanente de trabajadores que no tiene más posibilidades que iniciar pequeños negocios. Estas empresas comerciales se caracterizan por una escasez de capital y un alto nivel de intensidad de trabajo.

La idoneidad de la ECS para la economía avanzada puede compararse con la idoneidad de los trabajadores informales para la acumulación de capital en los sectores formales e informales de la economía. El uso de trabajadores informales es muy rentable para las empresas en el sector formal e informal. Los trabajadores informales pueden ser empleados para reducir las demandas salariales de los trabajadores formales, para aumentar las tasas de explotación (relación entre las ganancias y los sueldos o salarios) de los trabajadores formales, y para introducir medidas con el objetivo de aumentar la productividad y la intensidad del trabajo de los trabajadores formales. Los propios trabajadores informales también son fuentes de rentabilidad debido a las siguientes razones: (i) los salarios en el sector informal son más bajos que los salarios brutos en el sector formal; (ii) la ausencia de derechos laborales y de representantes sindicales hacen que las tasas de explotación en el sector informal sean más altas que en el sector formal; y, (iii) la inseguridad económica de los trabajadores en el sector informal hace que sea mucho más fácil aumentar la intensidad del trabajo. Gamero y Humala (2002, p. 72) señalan que, como resultado de los reducidos costos totales de producción causados por el trabajo informal, los salarios y sueldos de los trabajadores formales podrían disminuir ya que los costos de reproducción de estos trabajadores formales se han reducido.

La existencia de una amplia gama de pequeñas empresas informales es funcional para las corporaciones formales, ya que estas empresas suministran las corporaciones formales a un costo menor que otras compañías formales y realizan tareas al servicio de empresas formalmente establecidas a un costo menor que otros negocios formales (en términos de costos de mano de obra, costos de mantenimiento de maquinaria y equipo, etc.). La integración horizontal y vertical de negocios formales e informales queda demostrada por todo el conjunto de relaciones de subcontratación que existen

16 Según Díaz (2014, p. 197), "muchas de las microempresas existen básicamente como una respuesta al subempleo" [...]. Es muy probable que solo una proporción pequeńa de estas empresas cuente con potencial emprendedor". 
entre estas empresas (Semana Económica, 1982, pp.6-7; Grompone, 1991, pp. 81-82; Kolko, 1988, pp. 316-317, Mukherjee, 2016, pp. 22-23).

\section{El mercado interno peruano y la ECS}

La ECS comprende procesos de producción específicos y mercados propios. La segmentación del mercado laboral está acompañada por la segmentación de los mercados de consumo. Los trabajadores sobreexplotados no solo contribuyen a un aumento de las ganancias empresariales en general, sino también ayudan a la creación de un mercado de mercancías de relativa calidad. Esto nos lleva al mercado interno peruano.

El mercado interno peruano puede dividirse en mercados para la economía avanzada y mercados que pertenecen a la ECS. Lo que podría denominarse como el mercado avanzado abarca el mercado externo y los mercados nacionales de alta calidad. Las microempresas no solo se relacionan con los procesos de producción y los mercados de la economía avanzada, sino también producen para sus propios mercados de bajos ingresos. Los bienes y servicios que se proporcionan en estos mercados son de calidad relativamente baja y ayudan a mantener la reproducción de la fuerza de trabajo en la ECS a bajo costos.

El mercado interno peruano, en su conjunto, es muy pequeño. La gran mayoría de la PEA trabaja en microempresas y gana un sueldo o salario igual o cercano (inferior o superior) al nivel del salario mínimo nominal. De acuerdo con nuestras estimaciones, en el período 2007-2015 el ingreso real promedio per cápita fue alrededor de un 25\% más alto que el nivel del salario mínimo nominal (INEI, 2016b, p. 23; INEI, 2013c, p. 19).

El desarrollo del mercado interno está condicionado por el desarrollo de la economía mundial. En otras palabras, los ciclos internacionales de altibajos determinan la evolución del mercado interno. Desde 2004, el aumento del PBI y, en consecuencia, el aumento del tamańo del mercado interno, se deben principalmente a la demanda de los recursos minerales del país y la IED en los sectores extractivos. ${ }^{17}$ Las fuerzas económicas internas son demasiadas débiles para aumentar, por su propia cuenta, el tamaño del mercado interno. ${ }^{18}$

La mayoría de las empresas peruanas tienen definitivamente un interés en el desarrollo del mercado interno. La gran mayoría de estas empresas son muy pequeñas y

17 Según Jiménez (2012, p.83), en las últimas décadas el crecimiento económico se ha basado en los términos de intercambio favorable, el aumento de la demanda mundial y las inversiones extranjeras primordialmente dirigidas hacia la explotación de los recursos naturales.

18 Véase para un análisis comparativo sobre la necesidad de las economías atrasadas para desencadenar el progreso económico a través del comercio internacional, Furtado (1965, pp. 83-86). Véase para un análisis comparativo, Jiménez (2012, pp. 63-64, 68-69). 
no participan en el comercio internacional. Sin embargo, el propio carácter de estas empresas (baja productividad, bajos salarios) y la competencia de precios hacen que sea muy difícil aumentar el tamaño del mercado interno. Se puede argumentar, incluso, que estos factores causan una reducción permanente del mercado interno.

El capital internacional y las grandes corporaciones nacionales no están muy interesados en el desarrollo del mercado interno peruano. Sus actividades productivas están esencialmente determinadas por el mercado mundial (Dobb, 1970, p. 42; FitzGerald, 1981, p. 197). Como la función primordial del país y sus trabajadores es proporcionar las materias primas para el empresariado internacional (o el Norte global), no es necesario para las fracciones económicas dominantes en el mundo (incluidas las fuerzas económicas dominantes en el Perú) contribuir al desarrollo del mercado interno peruano (por ejemplo, aumentando las tasas de remuneración). Solo es necesario contar con mano de obra suficiente para la extracción de las materias primas del país. Las ganancias de la producción en el país se obtienen en los países capitalistas avanzados y en China. Emmanuel (1979, p. 171) argumenta que la exportación de una gran parte del excedente producido en países como el Perú priva a estas naciones de los medios para acumular y de crecimiento económico. Según Palma (1988, p. 37), el rol en la división internacional del trabajo de los países en la periferia del sistema capitalista mundial no permite una acumulación suficiente para proporcionar empleo a todos. Solo se estimulan aquellos sectores que sirven a los intereses de acumulación en los países en el centro del sistema capitalista mundial.

Las corporaciones transnacionales y las grandes empresas nacionales no están intencionalmente en contra del desarrollo del mercado interno peruano. Aunque ambos se benefician de la posibilidad de obtener ganancias en el Perú, sus objetivos no están íntimamente relacionados con el desarrollo del mercado interno. El desarrollo de un sector manufacturero fuerte, por ejemplo, no forma parte de los planes del empresariado internacional como tampoco de las grandes compañías nacionales. ${ }^{19} \mathrm{Y}$ es exactamente una potencialidad del sector manufacturero de establecer vínculos hacia adelante y hacia atrás que promuevan la integración y la articulación de la economía, que aumenten el empleo y que desarrollen el mercado interno (Gonzales de Olarte, 2016).

Cuando entendemos que el mercado interno peruano es muy pequeño, también se puede comprender que las crisis económicas en el Perú no son de sobreproducción. Las crisis económicas no son causadas por bajos niveles de demanda efectiva nacional o por bajo consumo sino so principalmente la consecuencia de los problemas económicos en el Norte global en general y de la reducción de las posibilidades del empresariado internacional para acumular capital en particular. Esta reducción es, primordialmente, la

19 Según Sunkel (, p. 167), solo la concentración industrial, la creación de grandes empresas y la producción industrial masiva ayuda a aumentar el mercado interno (expresado en un aumento sustancial y progresivo del ingreso nacional). 
consecuencia de la disminución de los precios y de los volúmenes de exportación de los minerales del país. La reducida posibilidad de extraer de manera rentable estos recursos, lleva a las corporaciones transnacionales a dejar de producir en el país y a disminuir sus inversiones.

\section{Conclusiones}

La estructura económica del Perú es muy difícil de cambiar. La estructura económica del país es la expresión de su papel en la división internacional del trabajo.

En este artículo se ha argumentado que la existencia generalizada de una ECS en el Perú es la barrera principal para la transformación de la estructura productiva del país. Sin embargo, la base estructural para el surgimiento de la ECS es el papel del Perú en la división internacional del trabajo. Por lo tanto, un cambio de la estructura productiva peruana debería comenzar, necesariamente, con un cambio del rol del país en el mundo capitalista globalizado.

Aunque el ascenso de una ECS en el Perú está estructuralmente relacionado con el papel del país en la división internacional del trabajo y su apariencia concreta fue el resultado de condiciones particulares, la propia existencia de la ECS fortalece el rol del Perú en el mundo capitalista globalizado como, esencialmente, un proveedor de recursos naturales y contribuye a reforzar la división de la economía peruana en una economía avanzada y una ECS. Esto no solo ha sido demostrado por la funcionalidad de la ECS para la economía avanzada, sino también por el reducido tamaño del mercado interno peruano y las dificultades estructurales que impiden su crecimiento.

El progreso económico duradero en el Perú es solo posible cuando se ha cambiado el papel del país en el mundo capitalista globalizado. Como no es posible cambiar este rol en el corto plazo, se deberían implementar, al menos, políticas estructurales duraderas que apunten a cambiar el rol del país en la división internacional del trabajo. Esto implica, necesariamente, un retorno del papel del Estado en la economía. Los flujos internacionales de capital deberían dirigirse hacia los principales sectores y ramas productoras de valor agregado, y se tendría que introducir políticas que transformen la ECS en una economía avanzada. 


\section{Referencias}

Bebbington, A. (2013). Extractive industries, socio-environmental conflicts and political economic transformation in Andean America. En A. Bebbington (coord.), Social conflict, economic development and extractive industry (3-26). New York: Routledge.

Cardoso, F.H. (1979). Imperialismo y dependencia en la América Latina. En R. Villarreal (coord.), Economía Internacional II. Teorias del imperialismo, la dependencia y su evidencia histórica (298-315). México: Fondo de Cultura Económica.

Cavero, O. (2017). El trabajo en una economía heterogénea y marginal: Un panorama general de la situación socio-económica de los trabajadores en el Perú. En O. Manky (coord.), Trabajo y sociedad. Estudios sobre el mundo del trabajo en el Perú (26-57). Lima: Pontificia Universidad Católica del Perú, CISEPA.

Crabtree, J. (2005). Alan García en el poder. Perú: 1985-1990. Lima: Ediciones Peisa S.A.C.

Cypher, J.M. y Dietz, J.L. (2009) The process of economic development. New York: Routledge.

Dancourt, O. (2016). Las vacas flacas en la economía peruana. Documento de Trabajo no. 428, Lima: PUCP, Departamento de Economia, Recuperado de http://files. pucp.edu.pe/departamento/economia/DDD428.pdf

DíAz, J.J. (2014). Formalización empresarial y laboral. En R. Infante y J. Chacaltana (coords.), Hacia un desarrollo inclusivo. El caso del Perú (173-259). Santiago de Chile: CEPAL and OIT.

Dовв, M. (1970). Capitalismo, crecimiento económico y subdesarrollo. Barcelona: Editorial Oikos.

Emmanuel, A. (1979). El intercambio desigual. Ensayo sobre los antagonismos en las relaciones económicas internacionales. México: Siglo XXI Editores, S.A.

Emmanuel, A. (1976). El intercambio desigual. Cuadernos de Pasado y Presente, no. 24, $1-32$.

FitzGerald, E.V.K. (1981). La economía politica del Perú, 1956-1978. Desarrollo económico y reestructuración del capital. Lima: Instituto de Estudios Peruanos.

Frank, A.G. (1971). Lumpenburguesía: lumpendesarrollo. México: Serie Popular Era.

Frank, A.G. (1966). The development of underdevelopment. Monthly Review, 18 (4), 17-31.

Furtado, C. (1980). La economía latinoamericana. Formación histórica y problemas contemporáneos. México: Siglo Veintiuno Editores S.A.

Furtado, C. (1965). Desarrollo y subdesarrollo. Buenos Aires: Editorial Universitaria de Buenos Aires. 
Gamero, Julio y Ulises Humala (2002). Empleo y microempresa en Lima metropolitana. Entre el desempleo y la sobrevivencia. Lima: Desco.

Gonzales de Olarte, E. (2016). Una economía incompleta. Perú 1950-2007. Análisis estructural. Lima: Fondo Editorial de la Pontificia Universidad Católica del Perú I Instituto de Estudios Peruanos.

Gonzales de Olarte, E. (2007). La economía política peruana de la era neoliberal 1990-2006. En Y. Murakami (coord.), Después del Consenso de Washington: Dinámica de cambios político-económicos y administración de recursos naturales en los paises andinos (11-37). Discussion Paper no. 2. Kyoto: Center for Integrated Area Studies.

Grompone, R. (1991). El velero en el viento. Politica y sociedad en Lima. Lima: Instituto de Estudios Peruanos.

Gudynas, E. (2011). Más allá del nuevo extractivismo: transiciones sostenibles y alternativas al desarrollo. En F. Wanderley (coord.), El desarrollo en cuestión: reflexiones desde América Latina (379-410). La Paz: Plural Editores.

INEI (2017), Perú: Estructura empresarial 2016, Lima: INEI.

INEI (2016a), Perú: Estructura empresarial 2015, Lima: INEI.

INEI (2016b). Evolución de la pobreza monetaria 2009-2015. Informe técnico. Lima: INEI.

INEI (2014), Perú: Estructura empresarial 2013, Lima: INEI.

INEI (2013a). "Micro, Pequeñas y Medianas empresas concentran más del $20 \%$ de las ventas. Recuperado de https:/www.inei.gob.pe/prensa/noticias/ micro-pequenas-y-medianas-empresas-concentran-mas-/imprimir/.

INEI (2013b), Perú: Estructura empresarial 2012, Lima: INEI.

INEI (2013c), Evolución de la pobreza monetaria 2007-2012. Informe técnico, Lima: INEI.

INEI (2008). IV Censo Nacional Económico 2008. Perú: Características económicas de las micro y pequeñas empresas en el año 2007. Lima: INEI.

JimÉnez, F. (2012). Empleo y mercado interno en el modelo neoliberal: una nueva hipótesis sobre el subdesarrollo. Recuperado de http://files.pucp.edu.pe/departamento/economia/LDE-2012-01-03.pdf

JimÉnEz, F. (2010), Economía nacional de mercado: una estrategia nacional de desarrollo para el Perú. En Opciones de politica económica en el Perú: 2011-2015 (327-370). Lima: Fondo Editorial Pontifica Universidad Católica del Perú

Kolko, J. (1988). Restructuring the world economy. New York: Pantheon Books.

LEwIs, A.W. (1955). Teoría del desarrollo económico. México / Bogotá: Fondo de Cultura Económica.

Mandel, E. (1975). Tratado de economía marxista. Tomo II. México: Ediciones Era S.A. 
Marini, R.M. (1985). Dialéctica de la dependencia. México: Serie Popular Era, no. 22, Ediciones Era S.A.

MukHerjeE, Deepraj (2016). Informal economy in emerging economies: not a substitute but a complement. International Journal of Business and Economic Development, vol. 4 (3), 16-27.

Palma, Diego (1988). La informalidad, lo popular y el cambio social. Lima: Desco.

Parodi Trece, C. (2010). Perú 1960-2000. Politicas económicas y sociales en entornos cambiantes. Lima: Centro de la Investigación de la Universidad del Pacífico.

Prebisch, R. (1949). The Economic Development of Latin America and its principal problems. Recuperado de http://www.rrojasdatabank.info/prebisch_theec-development.pdf

Reyna, C. (2000). La anunciación de Fujimori. Alan García 1985-1990. Lima: Desco.

Robinson, W.I. (2010). Latin America and global capitalism. A critical globalization perspective. Baltimore, Maryland: The Johns Hopkins University Press.

Rostow, W.W. (1961). Las etapas del crecimiento económico. Un manifiesto no comunista. México / Buenos Aires: Fondo de Cultura Económica.

SaAvedra Chanduvi, J. (1999). La dinámica del mercado de trabajo en el Perú antes y después de las reformas estructurales. Serie Reformas Económicas no. 27. Santiago de Chile: ECLAC.

Semana Económica (1982). Lo informal es muy formal. Semana Económica, 2 (76), $6-7$.

Sunkel, O. (1968). Política nacional de desarrollo y dependencia externa. En J. Matos Mar (coord.), La dominación de América Latina (129-175). Lima: Francisco Moncloa Editores S.A.

Yepes del Castillo, E. (1972). Perú 1820-1920. Un siglo de desarrollo capitalista. Lima: Instituto de Estudios Peruanos / Campodonicoediciones S. A. 